\title{
Knowledge and performance among nurses before and after a training programme on patient falls
}

\author{
Nagwa Younes Abou El Enein ${ }^{1}$, Azza Saad Abd El Ghany ${ }^{2}$, Ashraf Ahmad Zaghloul ${ }^{{ }^{*}}$ \\ ${ }^{1}$ Department of Health Administration and Behavioural Sciences, High Institute of Public Health, University of Alexandria, Alexan- \\ dria, Egypt \\ ${ }^{2}$ Health Insurance Organization, Alexandria, Egypt \\ Email: ${ }^{*}$ zaghloul.ashraf@gmail.com
}

Received 9 September 2012; revised 16 October 2012; accepted 16 November 2012

\begin{abstract}
Background: Patient falls in hospitals are common and affect approximately $2 \%$ to $17 \%$ of patients during their hospital stay. Patient falls are a nursingsensitive quality indicator in the delivery of inpatient services. Objective: To assess the effect of educational training program on nurses' knowledge and performance regarding prevention of fall at one of the health insurance organization hospitals in Alexandria. Setting: The study was conducted at 284 bed general hospital affiliated with the Health Insurance Organization in Alexandria. Design: A quasi-experimental design was followed. Participants: The study sample included all nurses of different ranks working at four departments namely, orthopedic, medical, surgical, ICU unit. Results: There was a significant difference regarding all factors under study before and after the educational programme except for two individual factors, old age $(p=0.84)$, overall poor health status $(p=0.38)$, and two health factors, uses aids $(p=0.50)$, treatment by heparin $(p=1.00)$, and two environmental factors, poor lighting $(p=0.34)$, loose cords or wires $(p=0.30)$ and bells $(p=0.30)$, and one miscellaneous factor, patient education $(p=0.85)$ and tidy environment $(p=0.85)$. All departments showed posttest performance improvement, the total performance median for departments regarding environmental factor $(p=0.04)$ and health education $(p=0.001)$. Conclusion: Education programmes should be regularly, updated in view of changing knowledge and work practices.
\end{abstract}

Keywords: Patient Falls; Nurse Knowledge; Performance; Quasi-Experimental Design

\section{INTRODUCTION}

Patient falls, defined as the rate at which patients fall

${ }^{*}$ Corresponding author. during their hospital stays per 1000 patient days, are a nursing-sensitive quality indicator in the delivery of inpatient services. Among the nursing quality indicators identified by the American Nurses Association (2002), patient fall rates are perceived as the indicator that could be most improved through nurse-led safety strategies or interventions [1]. Hospitals have devoted quality improvement and research efforts to prevent falls, but patient falls nonetheless consistently compose the largest single category of reported incidents in hospitals. Apparently the utilization of fall risk assessment tools to evaluate patients' risks for falls apparently are not effectively reducing inpatient fall rates because of human factors and ergonomics in a hospital environment [2]. Patient falls in hospitals are common and affect approximately $2 \%$ to $17 \%$ of patients during their hospital stay [3-7]. Fall related injuries occur in $15 \%$ to $50 \%$ of the patients, including major injuries such as fractures or lacerations in $1 \%$ to $10 \%$ [7-10]. Furthermore, falls may lead to fear of falling with subsequent activity restriction, prolonged hospital stay and legal liability [11]. Patient falls are a high-risk, high-volume, high-cost challenge for healthcare facilities. Nearly one-third of US adults ages 65 and older fall each year, according to the Centers for Disease control and Prevention (2008) [12]. Injuries from falls can lead to significant morbidity and mortality. Of those individuals who sustain a hip fracture-the most feared complication from a fall-more than $24 \%$ die within a year of the fall, and $50 \%$ never return to their normal level of functioning [13]. The Joint Commission emphasized that the process of establishing a comprehensive fall-reduction program must involve much more than connecting causes to cures. It was stated that any fall prevention interventions should be acknowledged and accepted by the nurses who work at the bedside to ensure successful implementation and improved outcomes [1].

Individual risk factors for falls are either intrinsic or extrinsic to the care recipient system. Intrinsic risk fac- 
tors are integral to the patient system and may be associated with age-related changes, including previous falls, reduced vision, unsteady gait, musculoskeletal system deficits, mental status deficits, acute illness, and chronic illness. Extrinsic risk factors are external to the patient system and related to the physical environment, including medication, lack of support equipment by bathtubs and toilets, design of furnishings, condition of floors, poor illumination, inappropriate footwear, improper use of devices, and inadequate assistive devices [2-13]. In addition, it had been found that the primary root causes of fatal falls as reported by health care organizations involved inadequate staff communication, incomplete orientation and training, incomplete patient assessment and reassessment, environmental issues, incomplete care planning, unavailable or delayed care provision, and an inadequate organizational culture of safety $[14,15]$.

Over the years, hospitals have incorporated many methods and techniques aimed at reducing fall rates. Often, falls prevention programs or falls risk assessment tools are utilized to help reduce falls. Falls prevention programs can function to educate both nurses and patients about factors that cause falls and the injuries that result from falls. Falls assessments tools include: The Morse Fall Scale, the STRATIFY tool, the Hendrich II Fall Risk Model, and the Schmid Fall Risk Assessment Tool [16]. Nurses bear the primary responsibility regarding patient care and, therefore, assume accountability when patients do fall. Nurses often find themselves overburdened with the number of patients under their care, and the current technology used in hospitals can be confusing, thus lowering the efficiency of the nurses in the hospital [16,17]. Nurses working in public health, primary health care setting and home care are ideally positioned to help their patients acquire the skills and knowledge that can help them reduce their risk of injury. Nurses working in emergency rooms can gather important information about the causes of injuries. Nurses working in acute care can play an important role in preventing further injuries by starting the educational process with their patients [18]. Nurses can have a significant impact on injury prevention, as well as on successful treatment and rehabilitation after injuries have occurred. They possess characteristics which are effective in this role; as nurses have a strong skill base in assessment, skilled educators, present in all parts of the health system, and often have long term relationships with patients [14]. In addition nurses themselves are at high risk of certain kind of injuries, such as musculoskeletal injuries as a result of lifting heavy patient, and needle stick injuries [17]. Since in-patient falls and associated injuries frequently occur in hospital settings various initiatives have been undertaken to prevent these often harmful events in order to provide safe patient care. A first review in the 1980's of 6 studies on in-patient fall risk profiles and interventions to prevent in-patient falls in hospital settings gave some indications of potentially successful approaches. The few intervention studies conducted in acute care settings such as in medical, orthopedic and geriatric-psychiatric units showed a reduction in the incidence of falls [19]. No previous research has ever been conducted on falls prevention at the Health Insurance Organization Hospitals. The aim of the study was to investigate nurses' knowledge and performance to prevent patient fall at one of the Health Insurance Organization Hospitals.

Aim of the work: To assess the effect of an educational training program on nurses' knowledge and performance regarding prevention of fall at one of the health insurance organization hospitals in Alexandria.

\section{METHODOLOGY}

\subsection{Study Setting}

The study was conducted at one of the health insurance organization hospitals (284 bed general hospital), which is located in the eastern district of Alexandria. Nurses participated in the study from a variety of units namely; (orthopedic, medical, surgical, ICU unit). Data collection took place between February till May 2011.

\subsection{Study Design}

Quasi-experimental design (pre-post-intervention).

\subsection{Study Population}

Nurses of different ranks, ranging from registered nurses to diploma nurses (graduated from school of nursing) and specialized nurses who are working at different departments (orthopedic, medical, surgical, ICU unit).

\subsection{Sampling Design}

All the nurses working at four departments of the highest rate of patient liable to fall namely orthopedic, medical, surgical, ICU unit were included to assess their knowledge and performance regarding patient fall. The total number was 40 nurses: 10 Registered nurses and 30 technical nurses. One nurse was selected daily to be observed five times in order to observe her performance in prevention of patient fall at different times during the day work.

\subsection{Data Collection Tools}

Two tools were designed specifically to collect data of the present study. The first tool was used to assess knowledge of all nurses about prevention of patient fall before the educational training program and assess 
knowledge of selected nurses after the educational training program. A questionnaire was used as a tool for data collection for both pre- \& post-test phases of the training program in order to measure the knowledge level of the trainees regarding fall prevention. Nurses were assessed regarding the gained knowledge after the program by using the same tool. This questionnaire was designed by the researchers after reviewing the body of literature on patient fall $[12,13,20]$ after introducing the relevant modifications. The questionnaire consisted of two parts; part 1 included the demographic characteristics of nurses including; department, age, years of experience, and qualification degree, (previous training program in hospital hazard and reported cases). Part 2 was concerned with nurses' knowledge regarding fall prevention and consisted of 34 closed ended questions. Questions covered four factors, individual factors (6 questions), health factor (7 questions), environmental factors (9 questions), and other factors (12 questions).

Individual factors included namely; old age, history of fall, overall poor health status, urine incontinence, osteoporosis, bed ridden patient. Health factors included namely; uses aids, medications on neurological system, treatment by heparin, motion troubles, awareness troubles, seizures, heart attack, post operative. Environmental factors included namely; poor lightening, bed barriers, furniture, safe ends, carpenters, loose cords or wires, close tools (patient equipment), location of patient room, logo for patient identification, bells and announcement (bed alarm). Other factors included namely; patient education, tidy environment, availability of equipment, routine round, helmet hat (head cover), incomprehensive communication, insufficient training, incomplete patient evaluation, unsafe environment, insufficient care, absence of laws and regulations and no guidance plates.

The second tool was used to assess the skills of nurses regarding prevention of patient fall before and after educational training programme. A nurse performance observation checklist was used to observe the nursing staff on a Done/Not done scale where Done $=1$, Not done $=0$ for patients at risk of falling. The tool was developed by the researchers after reviewing the related literature [2, 12] to assess nurses' level of performance regarding prevention of patient fall. It consisted of 34 items; 11 education items and 22 environment items. The education items namely; orient patient to surroundings and assigned staff, instruct to call for help before getting out of bed, demonstrate nurses' call system, ambulate as early and frequently as appropriate for the patient's condition, educate and supply patient and family with fall prevention information, consult with the falls team and pharmacy (review medications, evaluation by the interdisciplinary team, exercise/activities program, actively engage patient and family in all aspects of the fall preven- tion program, instruct patient in all activities prior to initiating, and instruct patient in use of grab bar. The environment items namely; adequate lighting to provide safe ambulation, non-slip footwear, call bell within reach, visible, and patient informed of the location and use, light cord within reach, visible, and patient informed of the location and use, consider use of sitters for cognitively impaired patients, provide physically safe environment, i.e., eliminate spills, clutter, electrical cords, and unnecessary equipment, personal care items within arm length, bed in lowest position with wheels locked, identify patient in fall prevention program, i.e., colored wrist band, themed sign outside patient's room and above patient bed, every 3,2, or 1 hour comfort and toileting rounds, comfort rounds include positioning as indicated; offering fluids, snacks when appropriate and ensuring patient is warm and dry, wheelchair alarm, room placement closer to nurses' station, bedside mat, elevated toilet seat, for risk of head injury consider a helmet (for patients with a history to fall hitting head), assign bed that enables patient to exit towards stronger side whenever possible, individualize equipment specific to patient needs, minimize distractions, check tips of canes, walkers, and crutches for non-skid covers, and transfer towards stronger side.

The educational programme to upgrade knowledge and performance of nurses regarding prevention of patient fall was developed by the researchers after reviewing the related literature $[1,5,20]$, which included one day workshop (6 hours) for every 10 nurses. Pre- and posttests were conducted in order to assess changes about knowledge and performance of nurses. The programme was piloted on 10 nurses $(5$ specialized nurses and 5 registered nurses) in order to test the clarity and applicability for the tools. Accordingly, the necessary modifications were performed.

The collected data were coded and entered into the computer for statistical analysis. Data were checked for errors during data entry. SPSS statistical package version 16.0 was used for statistical analysis. The $5 \%$ level of significance was used for the tests of significance. Test of normality was carried out for the quantitative scores which proved to be highly skewed thus nonparametric tests of significance were utilized accordingly. Wilcoxon test was used to compare the distribution of two related samples (pre- and post-intervention) regarding the nurse performance scores. Mean (\%) score calculated as follows:

$$
\frac{\text { Actual score }}{\text { Maximum score }} \times 100
$$

\subsection{Ethical Considerations}

Ethical principles that governed the study process:

- Objective from study was discussed with authorized 
management and formal clearance was assured before collecting data;

- All nurses who participated in the study were those who actually agreed to complete the study;

- Nurses were approached with a full description of the study and its aim, after which the nurses were free to participate in the study or reject;

- Confidentiality of the nurses was protected throughout the study.

\section{RESULTS}

Table 1 shows the characteristics of the sample under study. The mean age of the sample was $25.3 \pm 8.2$ and the highest percentage of nurses aged between 18 years to less than 25 years accounted for $55 \%$ of the total sample. The highest percentage of nurses had 1 to 5 years of experience $(52.5 \%)$ while the lowest percentage $(12.5 \%)$ had experience from 10 to more than 15 years. The mean years of experience for the sample was $6.6 \pm 5.5$. Regarding departments, $37.5 \%, 22.5 \%, 20 \%, 20 \%$, of nurses were working at ICU, Internal medicine, orthopedic and surgery respectively. The highest percentage of nurses were diploma graduates, i.e., graduated from nursing secondary school (45\%) while the least percentage were nurses with bachelor degree (B. Sc Nursing) and accounted for $25 \%$. Except for one nurse among the sample, all the nurses did not attend any previous training regarding patient fall.

Table 2 presents nurses' knowledge related to personal, health, environmental and other factors of patient fall pre- and post-educational programs. There was a significant difference regarding all factors under study before and after the educational programme. Regarding item analysis, the knowledge pertaining to all factors (34 factors) was improved after the program except for two individual factors, old age $(\mathrm{p}=0.84)$, overall poor health status $(\mathrm{p}=0.38)$, and two health factors, uses aids $(\mathrm{p}=$ $0.50)$, treatment by heparin $(\mathrm{p}=1.00)$, and two environmental factors, poor lighting $(\mathrm{p}=0.34)$, loose cords or wires $(p=0.30)$ and bells $(p=0.30)$, and one miscellaneous factor, patient education $(\mathrm{p}=0.85)$ and tidy environment $(\mathrm{p}=0.85)$.

Table 3 reveals nurses' performance median regarding the environment and health education factors per department, experience and qualification pre- and posteducational programs. All departments showed posttest performance improvement, the total performance median for departments regarding environmental factor $(p=0.04)$ and health education $(\mathrm{p}=0.001)$. A significant difference for performance was detected posttest for all years of experience, the total performance median for departments regarding environmental factor $(p=0.03)$ and health education $(\mathrm{p}=0.001)$. Regarding the qualifi-
Table 1. Personal characteristics of selected nurses at the health insurance organization hospital (Alexandria, 2011).

\begin{tabular}{lcc}
\hline Personal Characteristics & No & \% \\
\hline Age & 22 & 55.0 \\
- $18-24$ & 11 & 27.5 \\
- 25 - 34 & 7 & 17.5 \\
- $35+$ & & \\
Experience & 21 & 52.5 \\
- 1 - 4 & 7 & 17.5 \\
- 5 - 9 & 7 & 17.5 \\
- 10 - 14 & 5 & 12.5 \\
- $15+$ & & \\
Department & 15 & 37.5 \\
- ICU & 9 & 22.5 \\
- Internal medicine & 8 & 20.0 \\
- Orthopedics & 8 & 20.0 \\
- Surgery & & \\
Qualification & 10 & 25.0 \\
- Professional nurse (BSC) & 18 & 45.0 \\
- Diploma nurse & 12 & 30.0 \\
- Technical nurse & & \\
Training & & \\
- Yes & & \\
- No & & \\
\hline
\end{tabular}

cation, all categories of nurses scored a significant performance improvement. The total performance median for environmental factor $(p=0.02)$ and health education $(\mathrm{p}=0.001)$.

\section{DISCUSSION}

The present study aimed to assess effect of educational training programme on nurses' knowledge and performance regarding prevention of fall at one of the health insurance organization hospitals in Alexandria. Patient falls in hospitals are common and may lead to negative outcomes such as injuries, prolonged hospitalization and legal liability. Staff commonly directs patients as to how much assistance they require, however intrinsic patient factors such as cognitive impairment, inability to follow directions, confusion, and poor judgment may impede patient compliance with hospital staff recommendations. These factors have consistently been identified as significant risk factors for in patient falls [21-26]. However, various hospital fall prevention programs have been implemented in the last decades in hospitals which require predetermined awareness, education and training for all nurses working in direct contact with patients. Staff education is a crucial point in preventing patient falls, results 
Table 2. Nurses' knowledge related to personal, health, environmental and other factors of patient fall pre- and post-educational programs (Alexandria, 2011).

\begin{tabular}{|c|c|c|c|c|c|c|}
\hline \multirow{2}{*}{ Item } & \multicolumn{2}{|c|}{ Pre-program } & \multicolumn{2}{|c|}{ Post-program } & \multirow{2}{*}{$\%$ Change } & \multirow{2}{*}{$\mathbf{p}$} \\
\hline & No & $\%$ & No & $\%$ & & \\
\hline \multicolumn{7}{|l|}{ Individual factors (6 factors) } \\
\hline Old age & 38 & 95.0 & 40 & 100.0 & 5.0 & 0.845 \\
\hline History of fall & 7 & 17.5 & 40 & 100.0 & 82.5 & 0.001 \\
\hline Overall poor health status & 31 & 77.5 & 35 & 87.5 & 10.0 & 0.38 \\
\hline Urine incontinence & 11 & 27.5 & 39 & 97.5 & 70.0 & 0.001 \\
\hline Osteoporosis & 17 & 42.5 & 39 & 97.5 & 55.0 & 0.001 \\
\hline Bed ridden patient & 22 & 55.0 & 36 & 90.0 & 35.0 & 0.001 \\
\hline Mean \pm SD & \multicolumn{2}{|c|}{$52.5 \pm 19.1$} & \multicolumn{2}{|c|}{$95.4 \pm 7.5$} & -5.578 & 0.001 \\
\hline \multicolumn{7}{|l|}{ Health factors ( 7 factors) } \\
\hline Uses aids & 34 & 85.0 & 37 & 92.5 & 7.5 & 0.508 \\
\hline Medications on neurological system & 26 & 65.0 & 36 & 90.0 & 25.0 & 0.013 \\
\hline Treatment by Heparin & 5 & 12.5 & 25 & 62.5 & 50.0 & 0.001 \\
\hline Awareness troubles & 38 & 95.0 & 38 & 95.0 & 0.0 & 1.000 \\
\hline Seizures & 24 & 60.0 & 36 & 90.0 & 30.0 & 0.01 \\
\hline Heart attack & 14 & 35.0 & 26 & 65.0 & 30.0 & 0.01 \\
\hline Post operative & 24 & 60.0 & 39 & 97.5 & 37.5 & 0.001 \\
\hline Mean $\pm \mathrm{SD}$ & \multicolumn{2}{|c|}{$58.6 \pm 16.1$} & \multicolumn{2}{|c|}{$87.5 \pm 12.1$} & -5.37 & 0.001 \\
\hline \multicolumn{7}{|l|}{ Environmental factors ( 9 factors) } \\
\hline Poor lightening & 33 & 82.5 & 37 & 92.5 & 10.0 & 0.344 \\
\hline Bed barriers & 28 & 70.0 & 39 & 97.5 & 27.5 & 0.003 \\
\hline Furniture & 38 & 95.0 & 33 & 82.5 & -12.5 & 0.18 \\
\hline Safe ends & 29 & 72.5 & 39 & 97.5 & 25.0 & 0.006 \\
\hline Carpenters & 29 & 72.5 & 38 & 95.0 & 22.5 & 0.022 \\
\hline Loose cords or wires & 21 & 52.5 & 26 & 65.0 & 12.5 & 0.302 \\
\hline Location of patient room & 4 & 10.0 & 26 & 65.0 & 55.0 & 0.001 \\
\hline Logo for patient identification & 6 & 15.0 & 40 & 100.0 & 85.0 & 0.001 \\
\hline Bed alarm & 17 & 42.5 & 37 & 92.5 & 50.0 & 0.001 \\
\hline Mean \pm SD & \multicolumn{2}{|c|}{$57.8 \pm 20.4$} & \multicolumn{2}{|c|}{$88.5 \pm 13.7$} & -5.08 & 0.001 \\
\hline \multicolumn{7}{|l|}{ Other factors ( 12 factors) } \\
\hline Patient education & 38 & 95.0 & 40 & 100.0 & 5.0 & 0.854 \\
\hline Tidy environment & 19 & 47.5 & 37 & 92.5 & 45.0 & 0.001 \\
\hline Availability of equipment & 26 & 65.0 & 40 & 100.0 & 35.0 & 0.001 \\
\hline Routine round & 12 & 30.0 & 23 & 57.5 & 27.5 & 0.007 \\
\hline Helmet hat & 7 & 17.5 & 25 & 62.5 & 45.0 & 0.001 \\
\hline Incomprehensive communication & 16 & 40.0 & 40 & 100.0 & 60.0 & 0.004 \\
\hline Insufficient training & 11 & 27.5 & 40 & 100.0 & 72.5 & 0.001 \\
\hline Incomplete patient evaluation & 17 & 42.5 & 40 & 100.0 & 57.5 & 0.01 \\
\hline Unsafe environment & 22 & 55.0 & 40 & 100.0 & 45.0 & 0.01 \\
\hline Insufficient care & 16 & 40.0 & 40 & 100.0 & 60.0 & 0.001 \\
\hline Absence of Laws and regulations & 14 & 35.0 & 40 & 100.0 & 65.0 & 0.001 \\
\hline No guidance plates & 14 & 35.0 & 40 & 100.0 & 65.0 & 0.001 \\
\hline Mean \pm SD & \multicolumn{2}{|c|}{$48.1 \pm 19.5$} & \multicolumn{2}{|c|}{$65.4 \pm 4.9$} & -4.23 & 0.001 \\
\hline Total Mean \pm SD & \multicolumn{2}{|c|}{$54.2 \pm 13.8$} & \multicolumn{2}{|c|}{$84.2 \pm 7.3$} & -5.01 & 0.001 \\
\hline
\end{tabular}


Table 3. Nurses' performance mean and standard deviation regarding to environmental factor and health education per department, experience and qualification pre- and post-educational programs (Alexandria, 2011).

\begin{tabular}{|c|c|c|c|c|c|c|}
\hline & \multicolumn{3}{|c|}{ Environmental factor } & \multicolumn{3}{|c|}{ Health education } \\
\hline & Pretest median & Posttest median & $\mathbf{p}$ & Pretest median & Posttest median & $\mathbf{p}$ \\
\hline ICU & 47.8 & 60.9 & 0.05 & 21.8 & 63.6 & 0.004 \\
\hline Internal medicine & 43.4 & 82.6 & 0.04 & 21.8 & 80.0 & 0.001 \\
\hline Orthopedic & 37.3 & 84.75 & 0.02 & 14.5 & 79.1 & 0.001 \\
\hline Surgery & 44.3 & 75.65 & 0.03 & 23.6 & 86.4 & 0.001 \\
\hline Total & 43.9 & 74.8 & 0.04 & 21.8 & 79.1 & 0.001 \\
\hline \multicolumn{7}{|l|}{ Experience } \\
\hline $1-4$ & 39.1 & 79.1 & 0.01 & 20.0 & 80.0 & 0.01 \\
\hline $5-9$ & 45.2 & 74.9 & 0.02 & 27.3 & 83.6 & 0.01 \\
\hline $10-14$ & 41.7 & 77.4 & 0.02 & 21.8 & 70.9 & 0.01 \\
\hline $15+$ & 44.3 & 73.9 & 0.03 & 23.6 & 67.3 & 0.01 \\
\hline Total & 43.9 & 74.8 & 0.03 & 21.8 & 79.1 & 0.001 \\
\hline \multicolumn{7}{|l|}{ Qualification } \\
\hline Professional nurse & 44.3 & 51.3 & 0.04 & 22.7 & 38.2 & 0.02 \\
\hline Diploma nurse & 42.6 & 77.4 & 0.02 & 20.0 & 82.7 & 0.001 \\
\hline Technical nurse & 41.7 & 79.6 & 0.01 & 21.8 & 79.1 & 0.001 \\
\hline Total & 43.9 & 74.8 & 0.02 & 21.8 & 79.1 & 0.001 \\
\hline
\end{tabular}

of a study conducted in an acute hospital care [26] demonstrated that staff education was very important and that preventive strategies should be focused on patients' modifiable fall risk factors and the provision of organizational conditions and staff educational programmes which support a safe hospital environment. Contrary to the findings in this study, the majority of the nurses were diploma holders (i.e., low skills and low training) and a small number of technical nurses and both had no previous education or training on patient fall prevention. The implementation of the educational programme revealed significant results on both knowledge and performance raising the fact of updated curricula taught at nursing schools and whether they are consistent with the current issues and hospital statistics related to patient falls in Alexandria. Yet, increasing awareness and knowledge of health personnel towards patient falls is not the only issue, but overcoming the risk factors related to patient falls as inadequate caregiver communication, inadequate staff orientation and training, inadequate assessment and reassessment, unsafe care environment, and inadequate care planning and provision addressed in a study by Tzeng and Yin [27] are essential for the success of an interventional programme to reduce patient falls. Within the same context, not to mention the full commitment on behalf of the health professionals towards reducing one of the major patient safety issues in health organizations. The researchers believe that top management commitment and conducing a no fear environment are potent facilitators for behavior change in health organizations besides ongoing educational programmes. In conclusion, education programmes should be regularly, updated in view of changing knowledge and work practices.

\section{LIMITATIONS}

The small sample size restricts the liability of generalizing the results of the current study. The areas which did not show a significant improvement after the educational programme raises the issue of future steps for improvement and assessment of the learning strategies and methodologies adopted during the programme.

\section{REFERENCES}

[1] Dykes, P.C., Carroll, D.L., Hurley, A.C., Benoit, A. and Middleton, B. (2009) Why do patients in acute care hospitals fall? Can falls be prevented? Journal of Nursing Administration, 39, 299-304.

[2] Al-Aama, T. (2011) Falls in the elderly: Spectrum and prevention. Canadian Family Physician, 57, 771-776.

[3] Blank, W.A., Freiberger, E., Siegrist, M., Landendoerfer, P., Linde, K., Schuster, T., Pfeifer, K., Schneider, A. and Halle, M. (2003) An interdisciplinary intervention to prevent falls in community-dwelling elderly persons: Protocol of a cluster-randomized trial [PreFalls]. BMC Geriatrics, 11.

[4] Dykes, P.C., Carroll, D.L., Hurley, A., Lipsitz, S., Benoit, A., Chang, F., Meltzer, S., Tsurikova, R., Zuyov, L. and Middleton, B. (2010) Fall prevention in acute care hospitals: A randomized trial. JAMA, 304, 1912-1918.

[5] Mahoney, J.E. (1998) Immobility and falls. Clinics in 
Geriatric Medicine, 14, 699-726.

[6] Krauss, M.J., Nguyen, S.L., Dunagan, W.C., et al. (2007) Circumstances of patient falls and injuries in 9 hospitals in a Midwestern healthcare system. Infection Control and Hospital Epidemiology, 28, 544-550. doi:10.1086/513725

[7] Lake, E.T., Shang, J., Klaus, S. and Dunton, N.E. (2010) Patient falls: Association with hospital Magnet status and nursing unit staffing. Research in Nursing \& Health, 33, 413-425. doi:10.1002/nur.20399

[8] Batchelor, F., Hill, K., Mackintosh, S. and Said, C. (2010) What works in falls prevention after stroke? A systematic review and meta-analysis, Stroke, 41, 1715-1722. doi:10.1161/STROKEAHA.109.570390

[9] Halfon, P., Eggli, Y., Van Melle, G. and Vagnair, A. (2001) Risk of falls for hospitalized patients: A predictive model based on routinely available data. Journal of Clinical Epidemiology, 54, 1258-1266. doi:10.1016/S0895-4356(01)00406-1

[10] Fischer, I.D., Krauss, M.J., Dunagan, W.C., Birge, S., Hitcho, E., Johnson, S., Costantinou, E. and Fraser, V.J. (2005) Patterns and predictors of inpatient falls and fall-related injuries in a large academic hospital. Infection Control and Hospital Epidemiology, 26, 822-827. doi: $10.1086 / 502500$

[11] Hitcho, E.B., Krauss, M.J., Birge, S., Claiborne Dunagan, W., Fischer, I., Johnson, S., Nast, P.A., Costantinou, E. and Fraser, V.J. (2004) Characteristics and circumstances of falls in a hospital setting: A prospective study. Journal of General Internal Medicine, 19, 732-739. doi:10.1111/j.1525-1497.2004.30387.x

[12] Oliver, D., Hopper, A. and Seed, P. (2000) Do hospital fall prevention programs work? A systematic review. Journal of the American Geriatrics Society, 48, 16791689.

[13] Heung, M., Adamowski, T., Segal, J.H. and Malani, P.N. (2010) A successful approach to fall prevention in an outpatient hemodialysis center. Clinical Journal of the American Society of Nephrology, 5, 1775-1779. doi:10.2215/CJN.01610210

[14] Logan, P.A., Coupland, C.A., Gladman, J.R., Sahota, O., Stoner-Hobbs, V., Robertson, K., Tomlinson, V., Ward, M., Sach, T. and Avery, A.J. (2010) Community falls prevention for people who call an emergency ambulance after a fall: Randomised controlled trial. BMJ, 340, c2102. doi:10.1136/bmj.c2102

[15] Hignett, S. and Masud, T. (2006) A review of environmental hazards associated with in-patient falls. Ergonomics, 49, 605-616.
[16] Morse, J.M., Black, C., Oberle, K. and Donahue, P. (1989) A prospective study to identify the fall-prone patient. Social Science \& Medicine, 28, 81-86. doi:10.1016/0277-9536(89)90309-2

[17] Boswell, D.J., Ramsey, J., Smith, M.A. and Wagers, B. (2001) The cost-effectiveness of a patient-sitter program in an acute care hospital: A test of the impact of sitters on the incidence of falls and patient satisfaction. Quality Management in Health Care, 10, 10-16.

[18] McFarlane-Kolb, H. (2004) Falls risk assessment, multitargeted interventions and the impact on hospital falls. International Journal of Nursing Practice, 10, 199-206. doi:10.1111/j.1440-172X.2004.00482.x

[19] Reiling, J. (2006) Safe design of healthcare facilities. Qual Saf Health Care, 15, i34-i40. doi:10.1136/qshc.2006.019422

[20] Tzeng, H.M. and Yin, C.Y. (2006) The staff-working height and the designing-regulation height for patient beds as possible causes of patient falls. Nursing Economics, 24, 279, 323-327.

[21] Tzeng, H.M. and Yin, C.Y. (2008) Heights of occupied patient beds: A possible risk factor for inpatient falls. Journal of Clinical Nursing, 17, 1503-1509. doi:10.1111/j.1365-2702.2007.02086.x

[22] Hurley, A.C., Dykes, P.C., Carroll, D.L., Dykes, J.S. and Middleton, B. (2009) Fall TIP: Validation of icons to communicate fall risk status and tailored interventions to prevent patient falls. Studies in Health Technology and Informatics, 146, 455-459.

[23] Koh, S.L., Hafizah, N., Lee, J.Y., Loo, Y.L. and Muthu, R. (2009) Impact of a fall prevention programme in acute hospital settings in Singapore. Singapore Medical Journal, 50, 425-432.

[24] Koh, S.S., Manias, E., Hutchinson, A.M., Donath, S. and Johnston, L. (2008) Nurses' perceived barriers to the implementation of a fall prevention clinical practice guideline in Singapore hospitals. BMC Health Services Research, 8, 105.

[25] Oliver, D., Hopper, A. and Seed, P. (2000) Do hospital fall prevention programs work? A systematic review. Journal of the American Geriatrics Society, 48, 1679-1689.

[26] Hendrich, A., Nyhuis, A., Kippenbrock, T. and Soja, M.E. (1995) Hospital falls: Development of predictive model for clinical practice. Applied Nursing Research, 8, 129139. doi:10.1016/S0897-1897(95)80592-3

[27] Rao, S.S. (2005) Prevention of falls in older patients. American Family Physician, 72, 81-88. 